\title{
KEANEKARAGAMAN HERBACEUS DI HUTAN PENDIDIKAN DAN PELATIHAN UNIVERSITAS MUHAMMADIYAH BENGKULU KABUPATEN BENGKULU TENGAH
}

\author{
Pariyanto $^{1}$, Rahmi $^{2}$ dan Rika Adisma ${ }^{3}$ \\ ${ }^{1,3}$ Program Studi Pendidikan Biologi Universitas Muhammadiyah Bengkulu \\ Jl. Bali I Kecamatan Teluk Segara Kota Bengkulu Post 38211 \\ ${ }^{2}$ Program Studi Pendidikan Biologi Universitas Riau Kepulauan \\ *Koresponden : Email : " pariyanto@umb.ac.id
}

\begin{abstract}
This study aims to determine the diversity of Herbaceous plants found in the forest Education and Training atMuhammadiyah University of Bengkulu, Central Bengkulu Regency. This research was conducted in January to February 2019 by using the coordinate points LS $03^{0} 40^{\prime} 10^{\prime \prime}$ BT $10^{\circ} 232^{\prime} 55^{\prime \prime}$. The method used in this study was a direct survey to the research location. The samplewas taken by exploring the research location. The identification of Herbaceous plants samples was did in the laboratory of Muhammadiyah University of Bengkulu. The data obtained was analyzed descriptively. The results of this study were found that it consist of 16 speciesfrom 9 families such as Th eAcanthaceae family, Amaranthaceae, Araceae, Astreaceae, Cleomaceae, Commelinaceae, Marantaceae, Musaceae, Zingiberaceae with a total of 1.052individuals. The species diversity index (H') at all levels has a value of 1.483 which is a medium categorywith ecological conditions namely an average temperature is $28^{\circ} \mathrm{C}, 86 \%$ air humidity, $6.5 \mathrm{soil} \mathrm{pH}$, and $25 \%$ soil moisture.
\end{abstract}

Keywords: Diversity, HerbaceousPlants, Forest in Education and Training at Muhammadiyah University of Bengkulu,

\section{ABSTRAK}

Penelitian ini bertujuan untuk mengetahui keanekaragaman tumbuhan Tumbuhan Herbaceus Yang Terdapat Di Hutan Pendidikan Dan Pelatihan Universitas Muhammadiyah Bengkulu Kabupaten Bengkulu Tengah. Penelitian ini telah di laksanakan pada bulan Januari sampai Februari 2019 dengan menggunakan titik koordinat LS 03 ${ }^{\circ} 40^{\prime} 10^{\prime \prime}$ BT $10^{0} 232$ '55". Metode yang digunakan dalam penelitian ini yaitu survei langsung kelokasi penelitian. Sedangkan pengambilan sampel di lakukan dengan menjelajahi lokasi penelitian. Identifikasi sampel tumbuhan herbaceus di laboratorium Universitas Muhammadiyah Bengkulu. Data yang di peroleh di analisis secara deskriptif. Hasil dalam penelitian ini di peroleh di temukan terdiri dari 16 spesies dari 9 famili yaitu famili Acanthaceae, Amaranthaceae, Araceae, Astreaceae, Cleomaceae, Commelinaceae, Marantaceae, Musaceae, Zingiberaceae dengan jumlah 1.052 individuIndeks Keragaman Jenis (H') pada semua tingkatan mempunyai nilai 1,483 yang termasuk kategori sedang. Dengan kondisi ekologi yaitu, suhu rata-rata $28^{\circ} \mathrm{C}$, kelembaban udara $86 \%$, pH tanah 6,5, dan kelembaban tanah $25 \%$.

Kata kunci: Keanekaragaman, Herbaceus, Hutan Pendidikan Dan Pelatihan Universitas Muhammadiyah Bengkulu. 


\section{PENDAHULUAN}

Separuh hutan yang ada di muka bumi tergolong sebagai hutan tropis. Hutan-hutan itu sangat beanekaragam terhadap tipe, komposisi, maupun strukturnya. Semua terjadi karena adanya variasi kondisi iklim dan tanah setiap wilayah. Ada hutan yang tumbuh dengan baik sehingga memiliki struktur lengkap mulai dari tumbuhan tingkat bawah sampai pohon yang tinggi 100 meter. Ada hutan yang tampak miskin dan tidak tumbuh dengan baik, sehingga produksi biomassa dalam setahun sangat rendah. Ada hutan rapat dengan tajuk pohon yang bertingkat-tingkat dan saling bersentuhan atau saling tindih. Di samping itu, ada juga hutan yang sangat jarang bahkan banyak kawasan hutan yang gundul (tidak berpohon) sehingga hutan tidak mampu menyajikan fungsinya secara optimal untuk kesejahteraan manusia (Indriyanto, 2008:1).

Tanaman herba ada yang memiliki batang terlihat jelas, misalnya Ciplukan (Physalis angulata) dan ada juga yang memiliki batang tidak jelas (roset) misalnya walangan (Eryngium foetidum) batang tanaman herba pada umumnya pada tidak meimiliki ruas-ruas batang, misalnya kapulaga (Amomum cordamomum), tumbuhan yang termasuk family Araceae (talas-talasan) Family Cryophyllaceae juga tumbuhan herba (Steenis, 2008:8).

Hutasuhut (2011:1) menambahkan bahwa belukar teduhan hutan hujan bukan hanya terdiri semak, herba dan kecambah pohon muda, tetapi termasuk juga paku-pakuan dan perdu. Menurut Richards (1981) dalam Hutasuhut (2011:1), tumbuhan bawah yang sering dijumpai dikawasan hutan hujan tropis terdiri dari famili Aracea, Gesneriaceae, Cammelinaceae, Urticaceae, Zingiberaceae, Begoniaceae, Rubiaceae dan tumbuhan-tumbuhan tingkat rendah seperti Dryopteri, Polypodium, Sellaginella dan lain-lain.

Herba merupakan tumbuhan pendek dengan tinggi rata-rata $2 \mathrm{~m}$ tidak mempunyai kayu dan memiliki batang yang basa karena mengandung banyak air. Menurut Hutasuhut (2011:4) herba merupakan tumbuhan tida berkayu yang tersebat dalam bentuk kelompok individu atau soilter pada berbagai kondisi habitat seperti tanah yang lembab atau berair, tanah yang kering, batu-batuan dan habitat dengan naungan yang rapat.

Berdasarkan survei awal dikawasan Hutan Pendidikan Dan Pelatihan Universitas Muhammadiyah Bengkulu Kabupaten Bengkulu Tengah. Banyak ditemukan berbagai jenis tumbuhan herbaceus seperti pisang hutan, walangan, dan lempuyang gajah namun untuk informasi jenis spesies yang ada di hutan ini masih sangat kurang, sehingga dirasa perlu untuk dilakukan penelitian mengenai keanekaragaman tumbuhan Herbaceus yang terdapat di Hutan Pendidikan Dan Pelatihan Universitas Muhammadiyah Bengkulu Kabupaten Bengkulu Tengah.

\section{METODE PENELITIAN}

Penelitian ini telah dilaksanakan pada bulan Januari sampai Februari 2019. Bertempat di Kawana Hutan Pendidikan dan Pelatihan Universitas Muhammadiyah Bengkulu Kabupaten Bengkulu Tengah. Dengan titik koordinat LS03 ${ }^{0} 40^{\prime} 10^{\prime \prime}$ BT $102^{0} 32^{\prime} 55^{\prime}$ ". Serta identifikasi di Laboratorium Biologi Universitas Muhammadiyah Bengkulu.Alat yang digunakan dalam penelitian adalah kantong plastik besar, sasak, Parang, kamera, gunting, mistar, kertas label, kertas Koran, tali rapia, pancang, meteran, termohygrometer, soil tester, GPS, dan buku catatan, sedangkan bahan yang digunakan adalah alkohol $70 \%$.Metode yang digunakan dalam penelitian ini adalah metode survei langsung lokasi penelitian di hutan Pendidikan dan Pelatihan Universitas Muhammadiyah Bengkulu Kabupaten Bengkulu Tengah dengan area seluas \pm 2.000 hektar dan yang akan diteliti pada titik koordinatLS $03^{0} 40^{\prime} 10^{\prime \prime}$ BT $102^{0} 32^{\prime} 55^{\prime}$. Sedangkan untuk pengambilan sampel pada penelitian ini dilakukan dengan cara menjelajah lokasi penelitian. Pengambilan sampel pada penelitian ini diambil dengan cara jelajah berdasarkan keberadaan tumbuhan herbaceus yang dianggap mewakili tempat tersebut .Setiap jenis tumbuhan herba yang ditemukan di lapangan diambil seluruh bagian tubuhnya yang meliputi data-data morfologi seperti akar, batang, daun, bungga, buah dan biji. Setiap sampel yang diambil difoto dan dibuat herbarium. Faktor ekologi yang diukur yaitu kelembaban tanah dan $\mathrm{pH}$ tanah diukur dengan soil tester, kelembaban udara dan suhu udara di ukur dengan termohygrometer. Identifikasi dilakukan dengan mencocokan sampel dengan menggunakan buku acuan diantarannya : Steenis, V(2008), Tjitrosoepomo, Gembong (2007).Data yang didapatkan di lapangan dianalisis dengan menggunakan rumus indeks keanekaragaman menurut Shannon-Wiener dalam (Soegianto, 1994) sebagai berikut:

Indeks keanekaragaman :

$$
\begin{aligned}
& \text { H'= }-\sum \text { pi log pi } \\
& \text { Keterangan : } \\
& \text { H' } \quad \text { indeks Shannon = indeks keanekaragaman jenis } \\
& \text { pi } \quad=\text { ni/N } \\
& \text { ni } \quad=\text { jumlah individu dari masing-masing spesies } \\
& \text { N } \quad \text { jumlah seluruh individu } \\
& \\
& \text { Menurut Fachrul (2012) menyatakan bahwa }
\end{aligned}
$$
kreteria yang digunakan untuk menginterpretasikan keanekaragaman jenis Shannon dan Winner yaitu:

a. $H^{\prime}<1$ : menunjukan bahwa keanekaragaman rendah

b. $1<H^{\prime}<3$ : menunjukan bahwa keanekaragaman sedang c. $H^{\prime}>3$ : menunjukan bahwa keanekaragaman tinggi.

Selanjutnya dari masing-masing keanekaragaman tumbuhan herbaceus diperbandingkan dan hasil perbandingan ini diketahui spesies mana yang mempunyai indeks keanekaragaman yang tinggi.

\section{HASIL DAN PEMBAHASAN \\ Hasil Penelitian}

Berdasarkan hasil penelitian yang telah dilakukan di Hutan Pendidikan Dan Pelatihan Universitas Muhammadiyah Bengkulu Kabupaten Bengkulu Tengah ditemukan 16 spesies tumbuhan herbaceus yang termasuk kedalam 9 famili. 
Tabel.1 Keanekaragaman Tumbuhan Herbaceus Yang Ditemukan.

\begin{tabular}{cllll}
\hline No & \multicolumn{1}{c}{ Famili } & \multicolumn{1}{c}{ Nama Latin } & \multicolumn{1}{c}{ Nama Indonesia } & Nama Daerah \\
\hline 1 & Acanthaceae & Asystasia gangetica & Rumput israel & Rumput israel \\
2 & Amaranthaceae & Amaranthus spinosus & Bayam duri & Bayam dughi \\
3 & Araceae & Alocasia micholitziana & Sander & Keladi \\
& & Alocasia alba & Keladi hutan & Keladi hutan \\
& & Ageratum conyzoides & Bandotan & Ghumput angit \\
4 & Asteraceae & Crassocephalun crepidioides & Sintrong & Cape \\
& & Mikania micrantha & Sembung rambat & Tetap tunggal \\
& & Sphagneticola trilobata & Wedelia & Ghumput bunge kuning \\
& & Synedrella nodiflora & Jotang kuda & Keghenyat daghat \\
5 & Cleomaceae & Cleome rutidosperma & Maman ungu & Maman ungu \\
6 & Commelinaceae & Commelina diffusa & Aur-aur & Aur-aur \\
7 & Marantaceae & Calathea makoyana & Kalatea liar & Kalatea liar \\
8 & Musaceae & Musa balbisiana & Pisang hutan & Pisang utan \\
9 & Zingiberaceae & Costus speciosus & Pacing tawar & Pacing \\
& & Etlingera megalocheilos & Tepus & Puae \\
& & Globba marantina & Lempuyang & Lempuyang \\
\hline
\end{tabular}

Dari tabel.1 dapat dilihat bahwa jenis tumbuhan herbaceus yang ditemukan terdiri dari 16 spesies dari 9 Famili yaitu (1) Famili : Acanthaceae1 spesies yaitu Asystasia gangetica(2) Famili : Amaranthaceae 1 spesies yaituAmaranthus spinosus (3)Famili : Araceae 2 spesies yaitu Alocasia micholitziana, Alocasia alba, (4) Famili : Astreaceae5 spesies yaitu Angeratum conyzoides, Crassocephalun crepidioides, Mikania micrantha, Sphagneticola trilobata,Synedrella nodiflora(5) Famili : Cleomaceae1 spesies yaitu Cleome rutidosperma (6) Famili : Commelinaceae1 spesies yaitu Commelina diffusa (7) Famili :Marantaceae 1spesies yaituCalathea makoyana
(8)Famili : Musaceae 1 spesies yaituMusa balbisiana(9)Famili : Zingiberaceae 3 spesies yaituCostus speciosus, Etlingera megalocheilos, Globba marantina.

Keanekaragaman jenis tumbuhan herbaceus dihutan dapat diketahui dengan menggunakan indeks keanekaragaman suatu spesies dalam kelompok tumbuhan tersebut semakin tinggi begitu juga sebaliknya nila nilai indeks keanekaragamannya kecil maka keanekaragamannya rendah. Hasil perhitungan indeks keanekaragaman dapat dilihat pada table 4.2 dibawah ini.

Tabel.2 Indeks Keanekaragaman Jenis (H') Tumbuhan Herbaceus Yang di Temukan.

\begin{tabular}{|c|c|c|c|c|c|}
\hline Nama Spesies & $\begin{array}{c}\text { Jumlah } \\
\text { Spesies } \\
\text { (ni) }\end{array}$ & $\mathbf{P i}$ & Log pi & Pi Log pi & H' \\
\hline Asystasia gangetica & 24 & 0,022 & $-1,658$ & $-0,036$ & 0,036 \\
\hline Amaranthus spinosus & 112 & 0,106 & $-0,974$ & $-0,103$ & 0,103 \\
\hline Alocasia micholitziana & 86 & 0,081 & $-1,091$ & $-0,088$ & 0,088 \\
\hline Alocasia alba & 98 & 0,093 & $-1,031$ & $-0,096$ & 0,096 \\
\hline Ageratum conyzoides & 97 & 0,092 & $-1,036$ & $-0,095$ & 0,095 \\
\hline Crassocephalun crepidioides & 51 & 0,048 & $-1,318$ & $-0,063$ & 0,063 \\
\hline Mikania micrantha & 62 & 0,059 & $-1,230$ & $-0,072$ & 0,072 \\
\hline Sphagneticola trilobata & 79 & 0,075 & $-1,124$ & $-0,084$ & 0,084 \\
\hline Synedrella nodiflora & 35 & 0,033 & $-1,481$ & $-0,048$ & 0,048 \\
\hline Cleome rutidosperma & 56 & 0,053 & $-1,275$ & $-0,067$ & 0,067 \\
\hline Commelina diffusa & 43 & 0,041 & $-1,387$ & $-0,056$ & 0,056 \\
\hline Calathea makoyana & 52 & 0,050 & $-1,301$ & $-0,065$ & 0,065 \\
\hline Musa balbisiana & 34 & 0,032 & $-1,494$ & $-0,047$ & 0,047 \\
\hline Costus speciosus & 47 & 0,044 & $-1,356$ & $-0,059$ & 0,059 \\
\hline Etlingera megalocheilos & 108 & 0,102 & $-0,991$ & $-0,101$ & 0,101 \\
\hline Globba marantina & 68 & 0,064 & $-1,193$ & $-0,076$ & 0,076 \\
\hline Total & 1052 & 0,939 & $-19,94$ & 1,483 & 1,483 \\
\hline
\end{tabular}

Berdasarkan penelitian yang dilakukan di Hutan Pendidikan Dan Pelatihan Universitas Muhammadiyah Bengkulu Kabupaten Bengkulu Tengah diperoleh indeks keanekaragaman jenis (H') yakni 1,483 jadi berdasarkan tabel diatas jumlah keanekaragaman tumbuhan herbaceus di hutan pendidikan dan pelatiha universitas muhammadiyah Bengkulu dikatagorikan indeks keanekaragaman sedang.

Faktor ekologi diukur pada saat penelitian di

Hutan Pendidikan Dan Pelatihan Universitas
Muhammadiyah Bengkulu Kabupaten Bengkulu Tengah yang dilakukan pada bulan Januari-Februari 2019. Data hasil pengukuran faktor ekologi dilokasi dapat dilihat pada tabel 4.3 dibawah ini. 
Tabel.3 Hasil Pengukuran Faktor Ekologi.

\begin{tabular}{clcccc}
\hline No & \multicolumn{1}{c}{ Faktor Ekologi } & Pagi & Siang & Sore & Rata-Rata \\
\hline 1 & Suhu Udara & $26^{0} \mathrm{C}$ & $30^{0} \mathrm{C}$ & $28^{0} \mathrm{C}$ & $28^{0} \mathrm{C}$ \\
2 & Kelembaban Udara & $90 \%$ & $78 \%$ & $89 \%$ & $66 \%$ \\
3 & $\mathrm{pH}$ tanah & 6,3 & 6,8 & 6,5 & 6,5 \\
4 & Kelembaban Tanah & $29 \%$ & $21 \%$ & $25 \%$ & $25 \%$ \\
\hline
\end{tabular}

Berdasarkan data faktor ekologi pada tabel .3 diatas, suhu pada lokasi penelitian di Hutan Pendidikan Dan Pelatihan Universitas Muhammadiyah Bengkulu Kabupaten Bengkulu Tengah berkisar rata-rata $28^{\circ} \mathrm{C}$, sedengkan faktor

\section{Pembahasan}

Berdasarkan hasil penelitian tumbuhan herbaceus yang telah dilakukan di Hutan Pendidikan Dan Pelatihan Universitas Muhammadiyah Bengkulu Kabupaten Bengkulu Tengah pada bulan Januari-Feberuaru 2019 yang ditunjukan pada tabel 4.1 diperoleh sebanyak 16 spesies dari 9 famili yaitu (1) famili : Acanthaceae1 spesies yaitu Asystasia gangetica (2) famili : Amaranthaceae 1 spesies yaitu Amaranthus spinosus (3) famili : Araceae 2 spesies yaitu Alocasia micholitziana, Alocasia alba, 4) famili : Astreaceae 5 spesies yaitu Angeratum conyzoides, Crassocephalun crepidioides, Mikania micrantha, Sphagneticola trilobata,Synedrella nodiflora (5) famili : Cleomaceae 1 spesies yaitu Cleome rutidosperma (6) famili : Commelinaceae1 spesies yaitu Commelina diffusa (7) famili :Marantaceae 1 spesies yaitu Calathea makoyana (8) famili : Musaceae 1 spesies yaitu Musa balbisiana(9) famili : Zingiberaceae 3 spesies yaitu Costus speciosus,Etlingera megalocheilos, Globba marantina.

Dari tabel tersebut dapat dilihat bahwa famili yang paling banyak ditemukan adalah famili Asteraceae dengan 5 spesies yaitu Angeratum conyzoides, Crassocephalun crepidioides, Mikania micrantha, Sphagneticola trilobata,Synedrella nodiflora.Famili Astreaceae banyak ditemukan karena persebaran spesies famili ini dipengaruhi oleh adaptaasi spesies yang mudah berkembang biak, pertumbuhannya yang cepat, variasi morfologinya terutama perbungaannya. Hal ini di dukung oleh (Ardianingsih, 2015) ia menyatakan persebaran spesies dipengaruhi oleh adaptasi spesies yang mudah berkembang biak. Spesies-spesies gulma umumnya tumbuh secara cepat dan dapat meningkatkan persaingan dengan spesies lain untuk mendapatkan nutrisi dan tempat sehingga dapat mendominan di tempat hidupnya. Serta juga didukung oleh (Ardianingsih, 2015) ia menyatakan ia menyatakan persebaran spesies dipengaruhi oleh variasi morfologi, terutama perbungaannya. Pada bunga tabung atau bunga pita yang menyusun perbungaan, terdapat poppus. Poppos ini tidak gugur dan tetap ditemukan ketika bunga telah berkembang menjadi buah. Buah yang memiliki poppus berupa rambut-rambut halus muda untuk disebarkan oleh angin. Biji dalam buah akan tumbuh dengan baik pada kondisi yang sama.

Famili yang relatif banyak yaitu famili Zingiberaceae 3 spesies yaitu Costus speciosus, Etlingera megalocheilos, Globba marantina. Famili Zingiberaceae banyak ditemukan karena famili ini dapat bersaing dengan tumbuhan lainnya.Selain itu famili Zingiberaceae tumbuh dengan subur di tempat yang lembab dan banyak ditemukan kelembaban udara diperoleh nilai berkisar rata-rata $86 \%$, $\mathrm{pH}$ tanah rata-rata 6,5 dan kelembaban tanah $25 \%$.

di dataran tinggi. Menurut Delta (2013) menyatakan bahwa famili Zingiberaceae merupakan tumbuhan dasar dari hutan tropis yang banyak ditemukan tumbuh ditempat yang rindang, lembab, dan banyak ditemukan didaerah pegunungan.

Famili yang ditemukan paling sedikit spesiesnya dilokasi penelitian ada 6 famili yaitu : (1) famili : Acanthaceae1 spesies yaitu Asystasia gangetica (2) famili : Amaranthaceae 1 spesies yaitu Amaranthus spinosus(3)famili : Cleomaceae 1 spesies yaitu Cleome rutidosperma (4) famili : Commelinaceae1 spesies yaitu Commelina diffusa (5) famili : Marantaceae 1 spesies yaitu Calathea makoyana (6) famili : Musaceae 1 spesies yaitu Musa balbisiana. Hal ini dikarenalan tajuk pohon yang ada dihutan juga mempengaruhi tumbuhan untuk mendapatkan cahaya matahari yang cukup untuk melakukan proses fotosintesis. Menurut fitriany (2012) tajuk pohon yang ada di hutan mempengaruhi jumlah jenis tumbuhan herbaceus disebabkan oleh adanya persaingan yang tinggi dengan pepohonan yang lebih besar.

Kemudian familirelatif sedikit ditemukan yaitu famili Araceae 2 spesies yaitu Alocasia micholitziana, Alocasia alba.Famili Araceae banyak ditemuka karena famili ini dapat beradaptasi dengan baik di tempat dataran rendah dan datara tinggi dengan tanah yang lembab dan intensitas cahaya yang tidak terlalu tinggi. morfologi tumbuhan araceae memiliki daun yang lebar dan juga tipis sehingga proses penguapan proses penguapan sangat tinggi sehingga tumbuhan dari famili Araceae ini cocok dihutan ini. Hal ini di dukung olehKhoirul (2014) menyatakan bahwa spesies famili araceae mampu tumbuh dengan kelebaban yang rendah hingga tinggi, sebaran dari famili araceae juga terkai dengan kemampuan beradaptasi terhadap kondisi lingkungan seperti suhu, kelembaban serta intensitas cahaya.

Dari tabel.2 diperoleh Indeks Keanekaragaman (H') tumbuhan herbaceus diperoleh indeks keanekaragaman (H') yaitu 1,483. Menurut Fachrul (2006) Indeks Keanekaragaman Jenis Shannon-Wiener mempunyai nilai, jika nilai H' lebih dari 3 menunjukkan keanekaragaman yang tinggi, nilai $\mathrm{H}^{\prime}$ lebih dari 1 atau sama dengan 1 namun kurang dari 3 menunjukkan keanekaragaman spesiesnya sedang dan jika nilai $H^{\prime}$ kurang dari 1 menunjukkan keanekaragaman sedikit atau rendah. Nilai 1,483 tersebut menunjukkan bahwa keanekaragaman tumbuhan Herbaceus di Hutan Pendidikan Dan Pelatihan Universitas Muhammadiyah Bengkulu Kabupaten Bengkulu Tengah tergolong Sedang, hal ini dikarenakan tumbuhan Herbaceus 
cocok hidup dilokasi penelitian yang bersuhu $28^{0} \mathrm{C}$ serta daya adaptasi yang tinggi terhadap faktor lingkungan. Hal ini sesuai dengan pendapat Fitriany dkk (2012) menyatakan bahwa tumbuhan herbaceus dapat tumbuh pada suhu antara $28^{\circ} \mathrm{C}-33^{\circ} \mathrm{C}$. selain itu Menurut Handayani (2004) dalam Hutahusut (2011) menyatakan bahwa keanekaragaman jenis herba yang sangat dipengaruhi oleh faktor lingkungan, Seperti suhu, kelembaban, tutupan tajuk dari pohon-pohon sekitarnya tingkat kompotisi dari masing-masig jenis herba tersebut. Bagi tumbuhan cahaya matahari merupakan salah satu faktor yang penting dalam proses perkembangan, pertumbuhan dan reproduksi.

Dari tabel.2. dapat dilihat bahwa spesies yang memiliki individu paling banyak ditemukan terdapat pada Amaranthus spinosusyaitu berjumlah 112 individu sehingga diperoleh indeks keanekaragaman $0.103 \mathrm{Hal}$ ini karena suhu udara dilokasi penelitian sesuai untuk pertumbuhannya yaitu $28^{\circ} \mathrm{C}$. Hal ini didukung oleh (Thomas, 1989) ia menyatakan tumbuhan bayam duri (Amaranthus spinosus $L$ ) tumbuh baik di tempat-tempat yang cukup sinar matahari dengan suhu udara antara $25^{\circ} \mathrm{C}-35^{\circ} \mathrm{C}$.

Dari tabel.2.dapat di lihat bahwa spesies yang memiliki individu paling sedikit terdapat padaAsytasia gangeticayaitu bejumlah 24 individu sehingga diperolah indeks keanekaragaman 0.036 . Hal ini dikarenakan $\mathrm{pH}$ tanah kurang sesuai dilokasi penelitian untuk pertumbuhannya yaitu 6,5. Hal ini didukung oleh (Grubben G.J, 2004 dalam

\section{KESIMPULAN}

Dari hasil penelitian tenteng Keanekaragaman Tumbuhan Herbaceus Yang Terdapat Dihutan Pendidikan Dan Pelatihan Universitas Muhammadiyah Bengkulu dapat disimpulkan bahwa:

1. Tumbuhan herbaceus yang ditemukan pada penelitian ini sebanyak 16 spesies dari 9 Famili 16 spesies.Famili yang paling banyak ditemukan adalah famili Asteraceae yang terdiri dari 5 spesies, Famili yang relatif banyak yaitu famili Zingiberaceae 3 spesies,Famili yang ditemukan paling sedikit spesiesnya dilokasi penelitian ada 6 famili yang terdiri dari 6 spesies, Famili relatif sedikit ditemukan yaitu famili Araceae 2 spesies, Spesies yang memiliki individu paling banyak

\section{DAFTAR PUSTAKA}

Ardianingsih, D. (2015). Keanekaragaman Famili Asteraceae Di Kawasan Kampus IPB Dermaga, Bogor. Skripsi. FMIPA ITB.

Adli A, N. (2014). Karakteristik Ekstrat Etanol Tanaman Rumput Israel (Asytasia Gengetica) Dari Tiga Tempat Tumbuhan Di Indonesia. Skripsi. UIN Syarif Hidayatullah.

Delta, M.A., Arbain, A. (2013). Study Jenis-Jenis Zingiberaceae Di Kawasan Hutan Lindung Gungung Talang Sumatera Barat. Jurnal Biologi UniversitasAndalas, Vol. 2 (3).

Fachrul, M. F. (2007). Metode Sampling Bioekologi. Jakarta: BumiAksara.

Fitriany, R. A., Suhadi, \& Sunarmi. (2000). Study Keanekaragaman Tumbuhan Herba Pada Area Tidak Bertajuk Blok Curah Jarak Di Hutan Musim
Adli A,N, 2014) ia menyatakan Asytasia gangeticadapat berkembang pada tanah aluvia pantai, dan $\mathrm{pH}$ yaitu 3,5-4.5.

Pada tabel.3 dapat dijelaskan bahwa faktor ekologi sangaat berperan penting dalam pertumbuhan tumbuhan herbaceus. Dari hasil pengukuran yang dilakukan di hutan pendidikan dan pelatihan universitas muhammadiyah Bengkulu di peroleh suhu berkisar rata-rata $28^{\circ} \mathrm{C}$, kelembaban udara berkisar rata-rata $86 \%, \mathrm{pH}$ tanah rata-rata 6,5 dan kelembaban tanah $25 \%$. Kondisi lingkungan seperti ini sangat cocok untuk tumbuhan herbaceus. Menurut Handayani (2004) dalam Hutahusut (2011) menyatakan bahwa keanekaragaman jenis herba yang sangat dipengaruhi oleh faktor lingkungan. Seperti suhu, kelembaban, tutupan tajuk dari pohon-pohon sekitarnya tingkat kompotisi dar masing-masig jenis herba tersebut. Bagi tumbuhan cahaya matahari merupakan salah satu faktor yang penting dalam proses perkembangan, pertumbubah dan reproduksi.

Dari hasil penelitian Keanekaragaman Tumbuhan Herbaceus Di Hutan Pendidikan Dan Pelatihan Universitas Muhammadiyah Bengkulu Kabupaten Bengkulu Tengah ditemukan masih sangat beragam hal tersebut dapat di lihat dari indeks keanekaragaman jenis (H'), oleh sebab itu sudah selayaknya kita menjaga keanekaragaman flora nusantara agar tetap terjaga kelestariannya dan sebagai sumbangan ilmu pengetahuan yang akan datang.

ditemukan terdapat pada Amaranthus spinosusyaitu berjumlah 112 individu,spesies yang memiliki individu paling sedikit terdapat pada Asytasia gangeticayaitu bejumlah 24 individu.

2. Berdasarkan penelitian yang di lakukan di Hutan Pendidikan Dan Pelatihan Universitas Muhammadiyah Bengkulu Kabupaten Bengkulu Tengah diperoleh indeks keanekaragaman jenis (H') yakni 1,483 dikatagorikan indeks keanekaragaman sedang, sedangkan faktor ekologi di peroleh suhu berkisar rata-rata $28^{\circ} \mathrm{C}$, kelembaban udara berkisar rata-rata $86 \%, \mathrm{pH}$ tanah ratarata 6,5 dan kelembaban tanah $25 \%$.

Taman Nasional Baluran. Biologi, Vol (1)(2) : 112.

Hutasuhut, M. (2011). Studi Tumbuhan Herba Hutan Sibayak 1. Tesis. Universitas Sumatera Utara. Medan.

Indrawan. 2012. BiologiKonservasi. Jakarta: Yayasan Pustaka Obor Indonesia.

Indriyanto. (2008). PengantarBudidayaHutan. Jakarta :BumiAksara

Indriyanto. (2010). Ekologi Hutan. .Jakarta :Bumi Aksara

Khadir, A. (2007). Keladialokasiahias. Jakarta: bumi aksara.

Khoirul, (2014). Identifikasi tumbuhan family Araceae di Cagar Alam Tangale Kabupaten Goruntalo, Thesis. Universitas Negeri Goruntalo. 
Kinho, J. (2011) kharakteristik morfologi Zingiberaceae di Cagar Alam Gunung Ambang di Sulawesi Utara. Info BPK Manado, Vol (1) 35-50.

Paryanto, 2012. Asosiasi Antar Spesies Dan Struktur Pohon Pada Habitat Bunga Bangkai (Amarphophallus titanium Becc) di Hutan Lindung Bukit Daun Register V Kabupaten Kepahiang Provinsi Begkulu. Tesis. Universitas Muhammadiyah Bengkulu. Bengkulu.

Pranita, D. (2014). Jenis-Jenis Tanaman Family Araceae di Kecamatan Seluput Rejang Kabupaten Rejang Lebong. Skripsi. Universitas Muhammadiyah Bengkulu.

Ridhwan. 2012. Tingkat Keanekaragaman Hayati dan Pemanfaatannya di Indonesia. Banda Aceh, Jurnal Biology Education. Page 1.

Sapuan (2005). Inventarisasi Jenis-Jenis Tumbuhan Lunak (Herba) yang Terdapat di Kawasan Hutan Desa Lubuk Belimbing II Di Kecamatan Kota Padang Kabupaten Rejang Lebong. Skripsi. Universitas Muhammadiyah Bengkulu.

Soegianto, Agoes. 1994. Ekologikuantitatif. Usaha Nasional. Surabaya.

Suhono, B.(2009). Ensiklopedia Flora. Jakarta: PT KarismaIlmu.

Susilowati, E. (2012). Perkembangan Dan Pertumbuhan Bayam Gulma Bayam Duri (Amaranthus spinosus
L) Pada Pemberian Ekstrak Kriyuh (Chromolaema odorata L) R.M. King \& H.E. Rob. Skripsi. Universitas Sebelas Maret Surakarta.

Steenis Van. 2008. Flora. PT. Penebar Swadaya. Jakarta.

Tjitrosoepomoe, G. (2005). TaksonomiTumuhanObatObatan. Yogyakarta: Gadjah Mada University Press.

Tjitrosoepomoe, G. (2007)a. Morfologi Tumbuhan.. Yogyakarta: Gadjah Mada University Press.

Tjitrosoepomoe, G. (2007)b.. Taksonomi Tumbuhan (Spermatophyte).. Yogyakarta: Gadjah Mada University Press.

Thomas A.N.S. 1989 Tanaman obat Tradisional. Yogyakatra: Kansius

Wahyuni, E. 2012. Jenis-Jenis Tumbuhan Herbaceus yang Terdapat di Kecamatan Pagar Jati Kabupaten Bengkulu Tengah. Skripsi. Universitas Muhammadiyah Begkulu.

Wijana. 2014. Biologi Dan Lingkungan. Singa raja: Plantaxia

Wikipedia, 2019. Mikania micrantha. (dikutip 10 Februari 2019). Di peroleh dari https://en.wikipedia.org/wiki/Mikania_micrantha. 